\title{
REVIEWS
}

\section{Progesterone signalling in breast cancer: a neglected hormone coming into the limelight}

\section{Cathrin Brisken}

Abstract | Understanding the biology of the breast and how ovarian hormones impinge on it is key to rational new approaches in breast cancer prevention and therapy. Because of the success of selective oestrogen receptor modulators (SERMs), such as tamoxifen, and aromatase inhibitors in breast cancer treatment, oestrogens have long received the most attention. Early progesterone receptor (PR) antagonists, however, were dismissed because of severe side effects, but awareness is now increasing that progesterone is an important hormone in breast cancer. Oestrogen receptor- $\alpha(E R \alpha)$ signalling and PR signalling have distinct roles in normal mammary gland biology in mice; both ER $\alpha$ and PR delegate many of their biological functions to distinct paracrine mediators. If the findings in the mouse model translate to humans, new preventive and therapeutic perspectives might open up.

$17 \beta$-oestradiol

The predominant form of oestrogen in the human body it is more abundant than oestrone and oestriol both in terms of serum levels and oestrogenic activity.
ISREC - Swiss Institute for Experimental Cancer Research, National Center of Competence for Molecular Oncology, School of Life Sciences, Ecole polytechnique fédérale de Lausanne (EPFL), SV2.832 Station 19, $\mathrm{CH}-1015$ Lausanne, Switzerland. e-mail: cathrin.brisken@epfl.ch doi: $10.1038 / \mathrm{nrc} 3518$
Breast cancer is increasingly being appreciated to be a complex disease. Pathologists have characterized 18 distinct histopathological subtypes ${ }^{1}$ and comprehensive molecular profiling has revealed four major classes of breast cancer ${ }^{2}$; particularly clinically relevant factors in this disease are tumour grade, hormone receptor status and the presence of ERBB2 (also known as HER2) amplification.

Evidence for enormous heterogeneity at the molecular level continues to accumulate, with exon and whole-genome sequencing of several hundred breast carcinomas revealing the presence of, on average, 300 mutations in the coding sequence per tumour but only a few genes that are frequently mutated across many tumours $^{2,3}$. This raises complex questions about driver versus passenger mutations, tumour cell heterogeneity ${ }^{4}$ and tumour evolution ${ }^{5}$.

The widely held view that mutations in breast epithelial cells drive mammary carcinogenesis, however, is questioned by observations of the Danish pathologist Maja Nielsen ${ }^{6}$. She sectioned entire breasts of women who had died of causes other than cancer and revealed that $30 \%$ of women in their forties had ductal carcinoma in situ (DCIS) or closely related precursor lesions ${ }^{6}$. The number of women who are actually diagnosed with breast cancer is substantially lower - one in eight (that is, $12.5 \%$ ) — indicating that only a subset of precursor lesions will progress to clinically relevant disease.
This is remarkable as DCIS is considered to be a direct precursor of invasive breast cancer, and comparative genomic hybridization has revealed the presence of extensive genetic alterations in DCIS that are similar to those found in nearby invasive lesions ${ }^{7}$. Thus, the presence of numerous mutations in breast epithelial cells, and even of a highly rearranged genome, is not sufficient to drive breast carcinogenesis. Additional factors must determine whether genetically altered cells progress to the state at which they provoke clinically manifest disease.

Experiments in mice and rats have shown that the ovarian steroid hormones, 17 $\beta$-oestradiol and progesterone, are pivotal in the control of breast development and physiology ${ }^{8,9}$, and both experimental and epidemiological studies indicate that the two hormones are intimately linked to mammary carcinogenesis. Hence, the dissection of their respective roles and understanding their mechanism of action could lead to the development of novel rational approaches for the prevention and treatment of breast cancer. The mouse mammary gland is a versatile experimental system that has been used to address these issues, in particular the complexities of endocrine versus paracrine signalling. The rat model, which is generally considered closer to that of the human breast, continues to have an important role in carcinogenesis studies (BOX 1). 


At a glance
- Mutations are not always sufficient to drive breast carcinogenesis but additional
factors determine whether genetically altered cells progress to the state during
which they provoke clinically manifest disease.
- The ovarian steroid hormones, $17 \beta$-oestradiol and progesterone, are pivotal in the
control of breast development and physiology and are intimately linked to mammary
carcinogenesis. Their respective roles in vivo have begun to be dissected in the
mouse model.
- $17 \beta$-oestradiol and progesterone act on a subset of cells that express the respective
receptors and elicit paracrine signalling.
- Progesterone has emerged as the major mitogen in the adult mammary epithelium in
both mice and humans.
- The major proliferative control axis progesterone-receptor activator of nuclear
factor- $\mathrm{KB}$ (NF- $\mathrm{KB}$ ) ligand (RANKL) is conserved between mice and humans.
- Interfering with progesterone receptor (PR) signalling and paracrine signalling holds
promise for breast cancer prevention and therapy.

\section{Reproductive hormones and breast cancer}

Reproductive physiology. Centuries ago, breast cancer was considered to be a disease of nuns, a population that generally has a healthy lifestyle but uncommon reproductive behaviour. Epidemiological studies revealed that early full-term pregnancies lowered the risk of developing breast cancer ${ }^{10}$. More recently, this was shown to be specific to progesterone receptor (PR)positive breast cancers ${ }^{11}$, which represent the majority of breast cancers. For all types of breast cancer, risk increases with early menarche (the establishment of menstrual cycles), late menopause and shorter menstrual cycles ${ }^{11}$; these factors all increase the number of menstrual cycles a woman experiences during her lifetime and hence the exposure time of the mammary epithelium to ovarian hormones.

The effect of menstrual cycles on breast cancer progression is strikingly illustrated by comparing the agespecific incidence of colon cancer with that of breast cancer. The incidence of both cancers increases exponentially up to the age of 50 - the average age at menopause - after which the increase continues unabated for colon cancer but slows for breast cancer. It has been estimated that six times as many women would succumb to breast cancer if there were no menopause ${ }^{12}$.

The hypothalamic-pituitary axis triggers changes in ovarian hormone levels during every menstrual cycle, with a pre-ovulatory, follicular phase characterized by an oestrogen peak, followed by a post-ovulatory, luteal phase, during which the body prepares for a potential pregnancy; the luteal phase is characterized by a smaller oestrogen peak and by high levels of progesterone (FIG. 1). If pregnancy occurs progesterone levels rise further; because of its high levels and prominent role throughout pregnancy, progesterone has been dubbed the 'pregnancy hormone'.

Several lines of evidence suggest that repeated exposure to luteal phase, and hence to increased serum progesterone levels, increases breast cancer risk. First, the breast is quiescent during the first part of the menstrual cycle, the follicular phase. A lot of confusion arises from calling the first part of the cycle the 'proliferative phase'. This term, however, is based on the changes that occur in the uterus: the endometrium proliferates before ovulation. Post-ovulatory secretion of progesterone has antiproliferative effects on the endometrium and induces secretory differentiation in the uterine lining (FIC. 1). In the breast, cell proliferation occurs during the luteal phase, and is accompanied by changes in the stroma ${ }^{13,14}$. Furthermore, this proliferation happens in the terminal ductal lobular units (TDLUs), anatomical structures at the distal ends of the human milk ducts. The finding that all breast cancers originate in the TDLUs, regardless of whether their histopathological label is 'lobular,' 'ductal' or other ${ }^{15}$, suggests that the changes during the luteal phase are related to the origin of breast cancer. Finally, the luteal phase is consistently 14 days long, whereas the duration of the follicular phase varies and is usually in the range of 10 to 21 days. Hence the increased risk of cancer that is related to shorter menstrual cycles correlates with more time spent in luteal phase.

Hormonal intervention. More than a century ago, the British surgeon George Beatson described regression of a breast tumour following ovariectomy ${ }^{16}$. In the 1960 s, pharmacological antagonists of both oestrogen and progesterone were developed. PR antagonists failed in the clinic because of severe side effects, such as liver toxicity. By contrast, drugs that interfere with oestrogen signalling, such as tamoxifen, which was introduced in the 1970s, and aromatase inhibitors, which were introduced 20 years later, have become mainstays of breast cancer therapy; they substantially prolong survival and have saved many lives ${ }^{17}$.

Agonists for both receptors have been developed and are used for both contraception and hormone replacement therapy (HRT), but there are growing concerns that they may increase breast cancer risk. Women currently taking oral contraception are at an increased risk of breast cancer ${ }^{18}$. However, the term oral contraception covers a plethora of approaches, with natural hormones and synthetic agonists in different doses taken according to a multitude of regimens. Most studies do

\section{Box $1 \mid$ The rat model}

In general, the physiology of the rat more closely resembles human physiology than does the mouse. In particular, similarities in liver metabolism make the rat a popular model for preclinical drug discovery and toxicological studies.

The rat has been the mammary tumour model of choice for decades because tumours that mimic the histology of some human breast cancer subtypes can be reproducibly induced by chemical carcinogenesis, and these tumours show hormone dependence ${ }^{91}$ and express hormone receptors $^{92}$. Tumours that develop in the mouse mammary gland are mostly oestrogen receptor- $\alpha(E R \alpha)$ negative.

Importantly for mammary gland studies, the rat oestrous cycle is longer and more regular than that of mice, and pre-ovulatory and post-ovulatory phases can be readily distinguished. Furthermore, morphologically, the rat mammary gland bears more resemblance to the human breast than does the mouse mammary gland. 


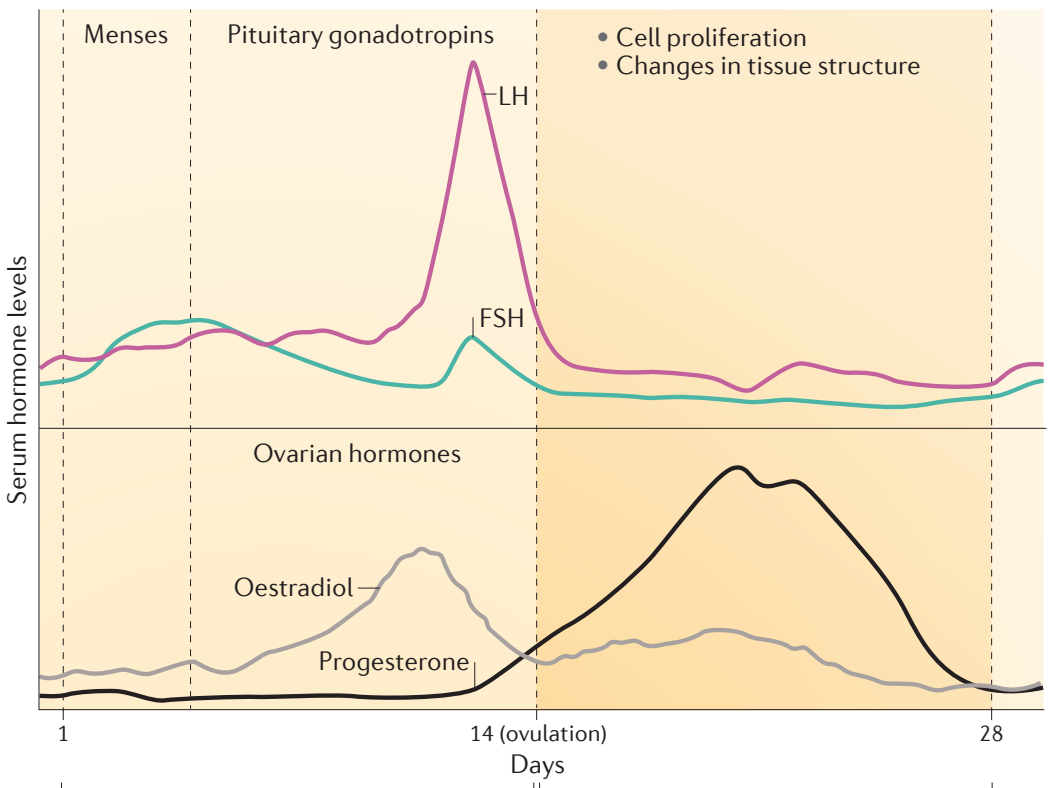

Ovaries:

Follicular phase

Proliferative phase

Quiescent phase
Luteal phase

Secretory phase

Proliferative phase
Breast:

Figure 1 | The menstrual cycle: serum hormone levels during a typical menstrual cycle together with changes in the breast. Note that the widely used term 'proliferative phase' is based on the uterine cycle during which the endometrium builds up before ovulation. In the breast, cell proliferation is observed during the post-ovulatory and luteal phase. The two major ovarian hormones, the oestrogens and progesterone, are closely intertwined. FSH, follicle-stimulating hormone; LH, luteinizing hormone.

not distinguish between these approaches, which could affect breast cancer risk in different ways. Moreover, it is conceivable that more differentiated analyses would identify risk factors, such as a woman's age or reproductive status, that are specific to particular types of contraception.

Women receiving HRT have little or no increase in breast cancer risk when taking oestrogens only, in fact there may even be a protective effect ${ }^{19}$. By contrast, a substantial increase in breast cancer risk was noticed in women taking combinations of an oestrogen and various synthetic progesterone agonists (progestins), despite this being standard of care in the United States and the United Kingdom ${ }^{20-22}$. This could be related to the increase in cell proliferation in the breast epithelium that has been reported with combination therapy ${ }^{23}$.

Studies from France revealed that postmenopausal women who took natural progesterone instead of synthetic progestins showed no statistically significant increase in breast cancer risk and that risk depends on the type of progestin used ${ }^{24,25}$. Progestins have longer half-lives than the unstable progesterone. This suggests that duration, level and molecular details of PR activation are important. Moreover, some progestins can bind to other nuclear receptors, including the androgen and the glucocorticoid receptors ${ }^{26}$, which further complicates the analysis. Alternatively, there may be special features of the postmenopausal breast that render it particularly susceptible to the effects of progestins

but not to the effects of progesterone. The decline in the use of HRT that followed the publication of these results has already caused a decrease in breast cancer incidence ${ }^{27}$ and, more specifically, the increased risk related to the use of oestrogen plus progestin declined soon after its discontinuation ${ }^{28}$. An interesting potential explanation is that progestin exposure promotes the progression of pre-existing lesions to invasive cancer, which is in line with Nielsen's findings ${ }^{6}$. Finally, high mammographical breast density, one of the strongest risk factors for breast cancer ${ }^{29,30}$ was correlated with progestin intake $\mathrm{k}^{31-33}$.

\section{Breast and mammary gland development}

The mechanisms by which oestrogens and progesterone act in vivo are difficult to disentangle because of the complexities of endocrine regulation with multiple interactions at the molecular, cellular, tissue and organismal levels. The breast is the only organ to develop mostly after birth, making it readily amenable to experimental manipulation. In addition, the mouse model provides unique experimental opportunities. Until puberty the mouse mammary gland consists of a rudimentary ductal system that is embedded in fatty stroma linked by a single primary duct to the nipple. At puberty, the milk ducts begin to expand into the mammary fat pad. During adulthood, with repeated oestrous cycles, the ductal system gains in complexity through side branching, which is strongly increased during early pregnancy. The last week of pregnancy is characterized by the sprouting of saccular outpouchings, called alveoli, which are destined to become sites of milk secretion (FIG. 2).

The anatomical structure of the human breast is more complex than the mouse mammary gland, with 10-25 primary ducts emanating from each nipple; these branch extensively and give rise to lobes. At the end of the ducts are the TDLUs, which are bottlebrush-like, branched structures that are surrounded by specialized intralobular stroma. Unlike the homogeneous adipose mammary stroma of the mouse, the human stroma is made of loose connective tissue that is highly vascularized and is separated from the interlobular stroma by fibrous connective tissue.

\section{Role of progesterone versus oestrogens}

Hormone ablation and replacement. Levels of endogenous progesterone and oestrogens can be depleted by ovariectomy, a simple surgical intervention in the mouse. As a result, cell proliferation in the mammary epithelium ceases and the epithelium eventually becomes atrophic. Experiments with such hormone-depleted animals have revealed that the administration of $17 \beta$-oestradiol is sufficient to induce cell proliferation in the pubertal gland, ultimately restoring ductal outgrowth, as is seen in intact pubertal animals ${ }^{34}$. However, when adult mice are ovariectomized and stimulated with $17 \beta$-oestradiol, the hormone barely induces any cell proliferation in the mammary gland ${ }^{35}$, whereas the combination of progesterone with $17 \beta$-oestradiol elicits substantial cell proliferation in adult mice that peaks at 48 hours of stimulation ${ }^{36}$. Little PR expression is detectable in ovariectomized mice ${ }^{37}$, 


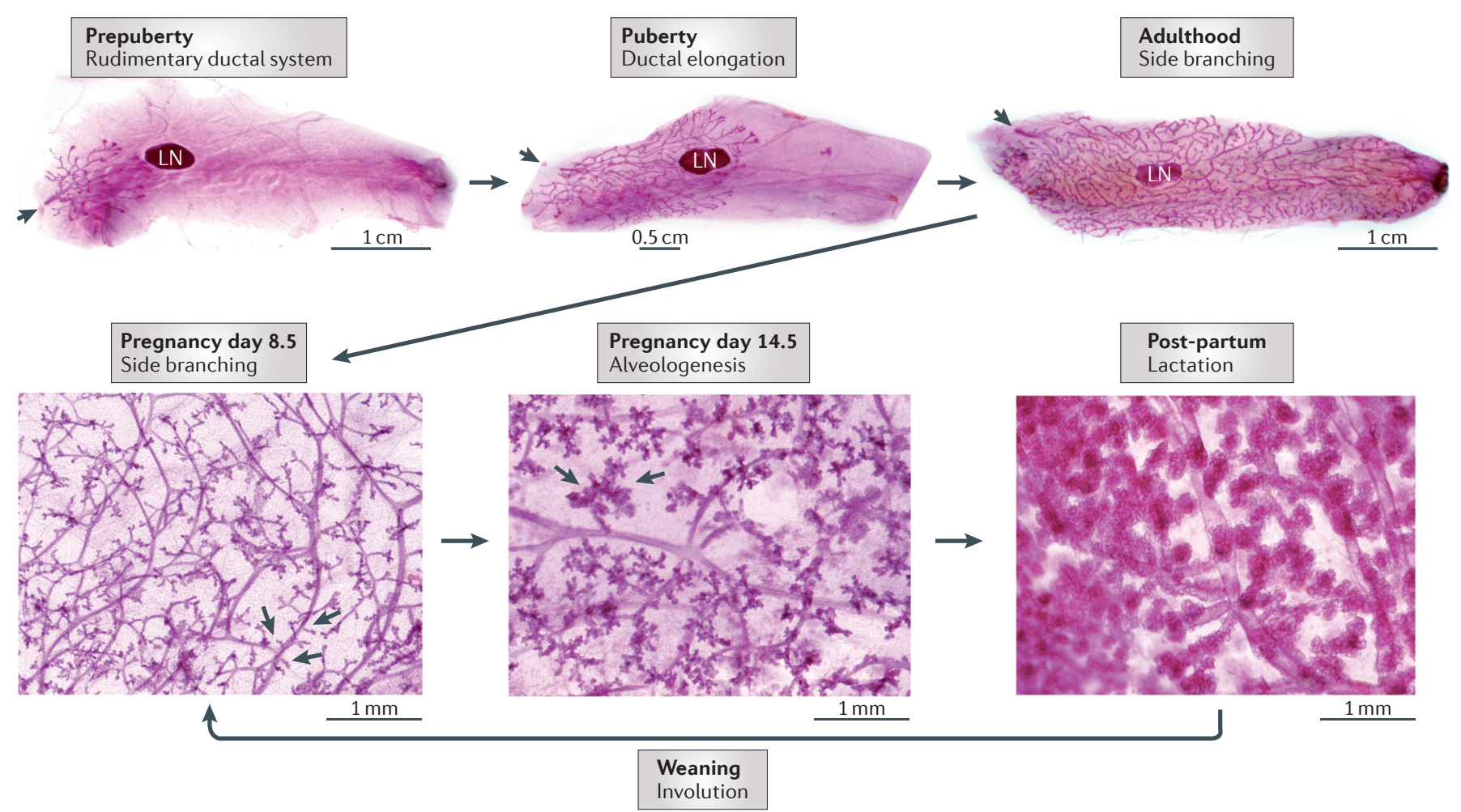

Figure 2 | Whole-mount stereographs of mouse inguinal mammary glands depicting distinct stages of mammary gland development. Until puberty the mammary gland consists of a rudimentary ductal system. The position of the nipple is indicated by arrowheads. During puberty ducts grow in the mammary fat pad by bifurcating. In adulthood, with repeated oestrous cycles, ductal complexity increases through side branching (arrows in pregnancy day 8.5 panel), which is enhanced during pregnancy. Later during pregnancy, alveologenesis (arrows in pregnancy day 14.5 panel) leads to an extensive increase in functional surface that is required for the secretion of copious amounts of milk during lactation. On weaning, the mammary gland involutes, which involves massive apoptosis, and returns to a pre-pregnancy state. LN, inguinal lymph node.

and progesterone on its own elicits little proliferation within 48 hours. This is expected because oestrogens are required for PR expression in the mammary epithelium $^{36}$. At later time points (3,5 and 10 days) proliferation in response to progesterone stimulation is observed ${ }^{38}$; however, with longer experimental hormone stimulation, levels of endogenous hormones may change, which could confound the analysis. Despite the caveat that ovariectomy creates nonphysiological conditions, these findings strongly suggest that oestrogens drive pubertal development, whereas progesterone is the major stimulus for cell proliferation in the adult mammary gland.

Genetic approaches. Mice either lacking oestrogen receptor- $\alpha(E R \alpha)$ or both isoforms of PR (BOX 2) have been generated through gene targeting in the germ line. Both mouse strains are viable but the mutant females have complex endocrine abnormalities ${ }^{39,40}$. Tissue recombination experiments with either mutant mammary stroma or epithelium grafted into endocrinecompetent animals (FIG. 3) showed that epithelial ERa signalling ${ }^{41}$ and epithelial $\mathrm{PR}^{42}$ signalling are required at subsequent stages of mammary gland development (reviewed in REF. 43). Indeed, in the absence of epithelial PR signalling in an otherwise PR-intact adult mouse, cell proliferation in the mammary epithelium is minimal ${ }^{35}$. Simplistically, it seems from the genetic experiment that ERa signalling, the main driver of pubertal growth, is relegated to a permissive function, as it is required for epithelial PR expression. However, because of the developmental block imposed by the germline deletion, additional functions at later stages could be masked. Resolving this issue awaits studies with lineage-specific conditional ERa deletion.

Mouse versus human. The usefulness of the mouse as a model for human disease is debated because of differences in the physiology and organ morphology between the two species. With regards to the hormonal regulation of the mammary gland, the findings in the mouse mentioned above are reminiscent of what can be observed in humans. The breast epithelium is quiescent during the follicular phase when serum oestrogen levels peak. Cell proliferation is observed during the luteal phase when high serum progesterone levels prevail. In fact, hormonal secretion follows a similar pattern in the two species, with a progesterone peak after ovulation ${ }^{44}$. However, the oestrous cycles of mice are not regular and are poorly delineated ${ }^{45}$.

The sequential requirement for the two hormones during development seems to be conserved: thelarche, the onset of breast growth in girls, is associated with 
increasing ovarian oestrogen secretion and precedes menarche, which reflects the onset of cyclic progesterone secretion. Mice and humans differ substantially in the details of their hormonal physiology; they have different hormone levels, different hormone processing by liver enzymes; different metabolites; and different regulation of aromatase, the enzyme that converts circulating androgens to oestrogens locally in the breast $^{46}$

Global gene expression profiling of the response to oestrogens and progesterone in mouse and human model systems has shown poor overlap and led to the suggestion that there are species-specific differences in hormonal regulation and downstream signalling. However, the experimental approaches also differed substantially in that most human work was carried out using cultured cells, whereas the work in mice was generally carried out in the whole organism. We have recently developed an ex vivo approach using reduction mammoplasty specimens and shown that in fresh breast tissue microstructures progesterone elicits cell proliferation whereas $17 \beta$-oestradiol does so only in a subset of the breast tissue samples ${ }^{47}$. Moreover, important downstream mediators of PR signalling that were identified in the mouse mammary gland but that were not induced in human three-dimensional cultures were also induced in the tissue microstructures that maintain cellular interactions. This suggests that the mouse mammary gland response to hormones is more similar to the human response than previously appreciated.

\section{Cellular mechanisms of steroid action} Cell-intrinsic proliferation versus paracrine proliferation. Across species, ER $\alpha$ and PR are absent from the myoepithelial cells and basal cells and are expressed by $30-50 \%$ of the luminal cells ${ }^{48,49}$. Most cells co-express $\mathrm{ER} \alpha$ and $\mathrm{PR}$, which is consistent with PR being an ERa target. A small subset of cells expresses either only ERa or only PR; whether this means a subset of cells uses a single receptor or whether it merely reflects the expression of these receptors at levels below the detection limit of immunohistochemistry is unclear. To simplify, I refer to cells expressing one or both receptors as hormone receptor-positive $\left(\mathrm{HR}^{+}\right)$cells throughout.

Myoepithelial cells and

basal cells

The two terms are often used interchangeably, but strictly speaking myoepithelial cells express markers for $\boldsymbol{\alpha}$-smooth muscle actin (aSMA), caldesmon, p63 and cytokeratin 5 or cytokeratin 6 and other high molecular mass cytokeratins. Basal cells are all the cells that do not touch the lumen hence they include subluminal cells and myoepithelial cells.

Luminal cells Cells that touch the lumen of the mammary ductal system.

\section{Box 2 | Progesterone receptor isoforms}

Progesterone receptor (PR) is expressed as two isoforms, PRA and PRB. PRB contains an additional 164 amino acids at the amino terminus. The two isoforms are generally expressed at similar levels in the breast but the ratio can be altered in human breast tumours, mouse mutants were generated and revealed that PRB is the functionally important form in the mammary gland, whereas PRA is important for ovarian function ${ }^{94}$. In reporter assays the two forms have distinct but overlapping transcriptional activities ${ }^{95}$. They have also been reported to be differentially expressed during mammary gland development ${ }^{96}$.
Studies in which freshly isolated, healthy human breast tissue samples were labelled with radioactive thymidine to mark proliferating cells revealed that most of the breast epithelial cells that incorporated the marked nucleotides were ERa- and PR-negative cells ${ }^{48}$. This dissociation of proliferation and HR expression was subsequently demonstrated in vivo, both in mice and in rats ${ }^{50,51}$, and this led to the suggestion that $\mathrm{HR}^{+}$cells function as organizers that may instruct their neighbours. The low propensity of $\mathrm{HR}^{+}$cells to proliferate has been linked to the presence in the subjacent extracellular matrix (ECM) of processed transforming growth factor- $\beta$ (TGF $\beta$ ) that activates TGF $\beta$ receptor (TGF $\beta$ R) signalling, leading to the accumulation of phosphorylated SMAD2 and SMAD3 in the nucleus ${ }^{52}$.

Genetic evidence from mouse models indicates that steroid hormones can indeed act by paracrine mechanisms; either $E s r 1^{-1-}$ (which encodes ERa) or $\mathrm{Pgr}^{-1-}$ (which encodes PR) mammary epithelial cells derived from the respective mutant animals, were mixed with wild-type cells to generate chimeric epithelia in cleared mammary fat pads. Receptor-deficient cells injected together with wild-type cells were able to contribute extensively to all aspects of mammary gland development. By contrast, receptor-deficient cells injected on their own could not ${ }^{41,42}$. Interestingly, when intact pieces of epithelial tissue from $\mathrm{Pgr}^{-1-}$ or wild-type animals were co-transplanted into the same fat pad, no rescue occurred, indicating that the $\mathrm{Pgr}^{-/-}$ mammary epithelial cells need to be in close proximity to wild-type cells for rescue to occur ${ }^{42}$. Hence, the factors implicated are not widely diffusible but function in a paracrine manner. This makes secreted factors such as WNTs, fibroblast growth factors (FGFs) and epidermal growth factor (EGF) family members attractive candidates but is also compatible with direct intercellular signalling mediated by Notch, ephrins or gap junctions.

Amphiregulin is an essential paracrine mediator of the cell proliferation induced by ER $\alpha$ at puberty ${ }^{53}$ and has also been linked to PR signalling in the rat mammary gland $^{54}$; WNT4 and receptor activator of nuclear factor- $\kappa \mathrm{B}$ (NF- $\kappa \mathrm{B}$ ) ligand (RANKL; also known as TNFSF11) have been established as important paracrine mediators of PR signalling ${ }^{35,55,56}$. Many other proteins have been implicated in mammary gland development by genetic experiments ${ }^{43}$ but how they connect to hormonal control mechanisms remains to be established in most cases. with the PRA isoform predominating ${ }^{93}$. Isoform-specific
Sensors and responders. Thus, the $\mathrm{HR}^{+}$cells seem to act as 'sensor' cells that translate the signals encoded by systemic hormones into local paracrine signals. To relay these signals they secrete paracrine factors that bind to receptors on $\mathrm{HR}^{-}$, luminal and basal cells, which act as the 'secondary responder cells'. This organizing principle ensures that the signal is amplified and prolonged in time and provides a means of coordinating different biological functions of distinct cell types.

On the basis of elegant experiments in MCF-7 cells that showed rapid degradation of ERa after activation by ligand and by DNA binding ${ }^{57}$ it was thought that HR 
a

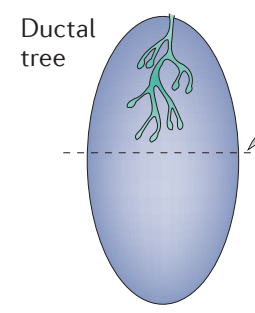

Three-week old mammary gland

b

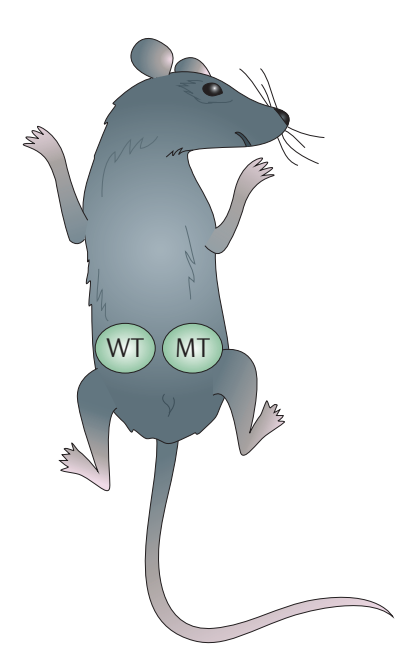

c

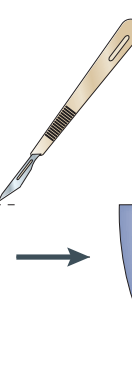

Cleared fat pad
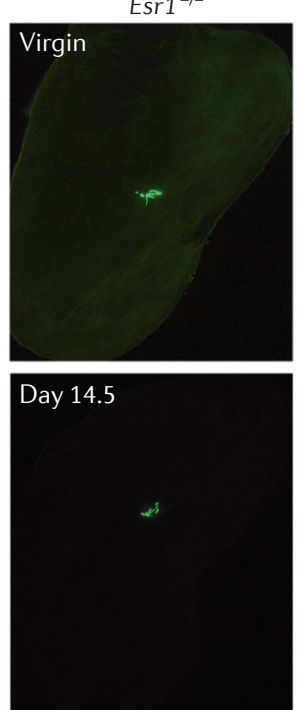

Piece of milk duct
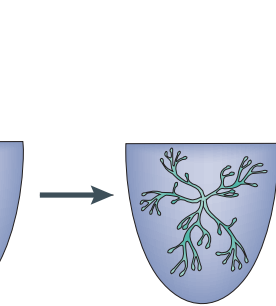

Reconstituted mammary gland

$\mathrm{Esr1}^{+/+}$
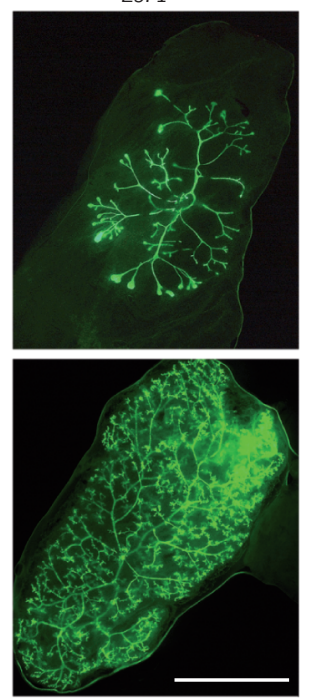

Figure 3 | Tissue recombination approach. a| In prepubertal mice, the part of the inguinal mammary gland near the nipple that contains the rudimentary ductal system can be readily removed by surgery and the remaining 'cleared fat pad' can be engrafted with mammary epithelium from donor mice that will reconstitute. $\mathbf{b} \mid \ln$ this way, wild-type (WT) mice can be generated in which the epithelium of one inguinal mammary gland specifically lacks a given gene (the mutant (MT) gland) while the contralateral side is engrafted with wild-type epithelium. $\mathbf{c} \mid$ An example of an experiment in which oestrogen receptor- $\alpha(E R \alpha)$-deficient $\left(E s r 1^{--}\right)$and $E s r 1$ wild-type epithelia derived from green fluorescent protein (GFP) transgenic females were grafted into contralateral cleared fat pads is shown. Mutant and wild-type grafts can be compared in a single host at different developmental stages such as puberty (top panels) and pregnancy day 14.5 (bottom panels) ${ }^{41}$. Shown are fluorescent stereomicrographs of the engrafted glands, scale bar: $5 \mathrm{~mm}$. Images are similar to those previously published in REF. 41 .

Bromodeoxyuridine (BrdU). An analogue of thymidine that can be incorporated into the newly synthesized DNA of replicating cells and is used to detect proliferating cells. expression was a transient cellular property; in other words, if a cell had recently been stimulated by oestrogens it would be $\mathrm{HR}^{-}$. Increasing evidence points to HR expression in vivo being a hallmark of a distinct cell type in the mammary epithelium. Strong support for this model comes from fluorescence-activated cell sorting (FACS) experiments, in which dissociated mammary cells were separated on the basis of differences in cell surface antigen expression. High CD24 glycoprotein expression marks luminal cells, whereas low CD24 expression marks myoepithelial cells ${ }^{58}$. The luminal $\mathrm{CD} 24^{\text {hi }}$ cells can be further separated on the basis of the expression of the cell surface marker stem cell antigen 1 (SCA1; also known as LY6A) ${ }^{59}$. The $\mathrm{SCA}^{+}{ }^{+}$population is enriched for $\mathrm{HR}^{+}$cells, whereas the $\mathrm{SCA1}^{-}$population comprises $\mathrm{HR}^{-}$cells; the two populations have distinct gene expression signatures that go well beyond ERa and PR target genes ${ }^{60}$. The $\mathrm{HR}^{-}$cells seem to be destined for milk secretion, as they show increased expression of milk protein genes and of the ETS-related transcription factor ELF5 that has been linked to the formation of secretory alveoli ${ }^{61}$. It is, however, conceivable that these expression signatures represent the sum of different subpopulations, $\mathrm{HR}^{+}$or $\mathrm{HR}^{-}$, which remain to be characterized.

The idea that HR status also defines different cell types in humans is supported by global gene expression profiling of breast tumours ${ }^{62}$. The major molecular subtypes are thought to reflect the stage in the mammary lineage from which the tumour was derived: a clinically rare stem cell-like type called claudin-low ${ }^{63}$; an $\mathrm{ER}^{-}$type resembling luminal progenitors called basal-like; and two differentiated types, an $\mathrm{ER}^{-}$type called molecular apocrine ${ }^{64}$, and finally the most common of breast tumours, an $\mathrm{ER}^{+}$type called luminal. ERBB2-positive tumours are equally distributed between the two differentiated types. As the basal-like tumours are negative for steroid receptors (ER and PR) and ERBB2, they are commonly called triple-negative breast cancer (TNBC).

\section{Progesterone-induced changes}

Given that recurrent menstrual cycles and repeated progesterone exposure increase breast cancer risk, it is important to understand which pathways progesterone activates as it impinges on the adult mammary gland through the $\mathrm{HR}^{+}$cells. The mechanisms by which progesterone triggers cell proliferation, activates progenitor cells, induces branching morphogenesis, affects immune cells, and controls the vasculature to ensure increased blood flow during the luteal phase and pregnancy are beginning to emerge in the mouse model (FIG. 4). I concentrate on the role of progesterone in cells in the $\mathrm{HR}^{+}$ cells - the sensor cells - in which ERa signalling is also active. Changes in oestrogen levels during the oestrous cycle impinge on all PR signalling activities and may be doing the fine-tuning (FIG. 4).

In contrast to tissues such as the skin or the intestine where epithelial cells proliferate, differentiate and then shed, in the mammary gland, newly generated cells in the milk ducts are not automatically shed as part of the process of maturation. Increases in cell number are required for side branches to form in the mouse mammary gland and for TDLUs to increase in complexity in the human breast. There is some cell death at the end of each menstrual cycle, and massive apoptosis leading to the loss of alveolar structures after weaning (FIG. 2).

Cell proliferation. Stimulation of ovariectomized female mice with progesterone (after an oestrogen pretreatment that is required to induce PR expression) elicits a first, small wave of bromodeoxyuridine (BrdU) incorporation in $\mathrm{PR}^{+}$cells, which is consistent with a cell-intrinsic mechanism (FIG. 5a). This is followed by a large wave of cell proliferation in $\mathrm{PR}^{-}$cells ${ }^{35}$ in line with the extra time required for synthesis and secretion 


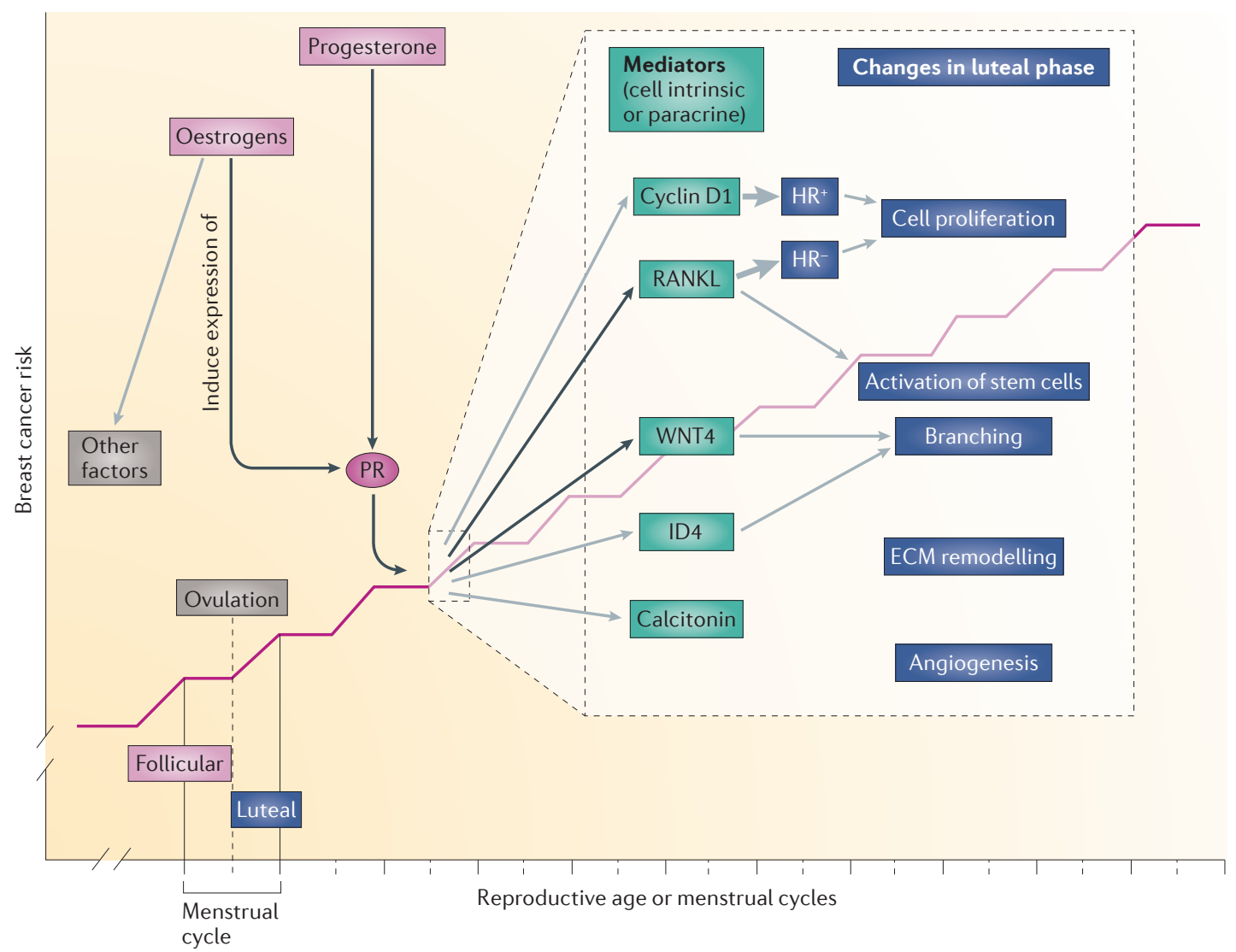

Figure 4 | Model: effect of menstrual cycles on breast cancer risk based on work in mouse models. Breast cancer risk is plotted over time, representative of a year during a woman's reproductive age. Every hormonal cycle there is some increase in breast cancer risk when progesterone serum levels increase during the luteal phase as shown for a representative cycle (dashed box). Oestrogens induce the expression of the progesterone receptor (PR) and may have other functions that remain to be discerned, these probably involve fine-tuning of progesterone action at the level of transcriptional modulation. Several downstream mediators receptor activator of nuclear factor- $\kappa \mathrm{B}(\mathrm{NF}-\kappa \mathrm{B})$ ligand (RANKL), cyclin D1, WNT4, calcitonin and inhibitor of DNA binding 4 (ID4) have been identified in the mouse. Genetic evidence has been provided that RANKL is required for progesterone-induced proliferation of hormone receptor (HR)cells and cyclin D1 is required for cell proliferation of $\mathrm{HR}^{+}$cells (bold grey arrows). RANKL has been implicated in the regulation of bipotential stem cells $s^{75,76}$ and shown to be required for side branching ${ }^{35}$. In Wnt4 $4^{-/-}$and Id4 ${ }^{-/-}$(REF. 82) mammary epithelia side branching is delayed. The role of calcitonin awaits further studies. Arrows in black indicate interactions that have been validated in humans ${ }^{43}$. ECM, extracellular matrix.

of a paracrine factor, and with the signal amplification resulting from diffusion of this factor to multiple surrounding cells (FIG. 5b).

Cyclin D1 (encoded by CCND1) amplification and overexpression occur specifically in $\mathrm{ER}^{+}$breast cancers $^{65}$ and have been associated with a poor prognosis and endocrine resistance ${ }^{66-68}$, suggesting a unique role of cyclin D1 in the context of the $\mathrm{HR}^{+}$cancers. To test whether cyclin D1 is particularly important in $\mathrm{HR}^{+}$cells, mice with contralateral cleared fat pads were reconstituted with $C c n d 1^{-/-}$versus wild-type epithelium, hormonally ablated and stimulated with progesterone ${ }^{35}$. The two types of proliferation, cell-intrinsic and paracrine proliferation, were observed in the wild-type graft but in the $C c n d 1^{-/}$epithelium proliferation of $\mathrm{HR}^{+}$cells was specifically impaired. Thus, the cell-intrinsic action of progesterone on $\mathrm{HR}^{+}$cell proliferation requires cyclin $\mathrm{D} 1$ (FIG. 5a), whereas the proliferation of $\mathrm{HR}^{-}$cells does not (FIG. 5b). Whether this relates to the cell cycle function of cyclin D1, be it catalytic or through the sequestration of p21 and p27, or the interactions of cyclin D1 with hormone receptors and their co-regulators (reviewed in REF. 69) remains to be elucidated.

Proliferation of $\mathrm{HR}^{-}$cells on progesterone stimulation requires RANKL (FIG. 5b), a tumour necrosis factor- $\alpha(\mathrm{TNF} \alpha)$ family member that was first isolated as being important for dendritic cells, which was shown to be important for osteoclast function ${ }^{70}$. Subsequently, RANKL was implicated in mammary gland development ${ }^{55}$. Its abrogation in the mammary epithelium of mice resulted in a lactation defect, which was linked to prolactin receptor signalling via inhibitor of NF- $\kappa B$ kinase- $\alpha(\mathrm{IKK} \alpha)^{71}$. However, RANKL expression is strongly induced by $\mathrm{PR}$ signalling and required for PR-induced side branching ${ }^{72,73}$. The protein is expressed specifically in $\mathrm{PR}^{+}$luminal cells ${ }^{73}$. Induction of RANKL expression in $\mathrm{ER}^{+}$mammary epithelial cells of $\mathrm{Pgr}^{-1-}$ females by means of an elegant inducible 
a Cell proliferation: direct action

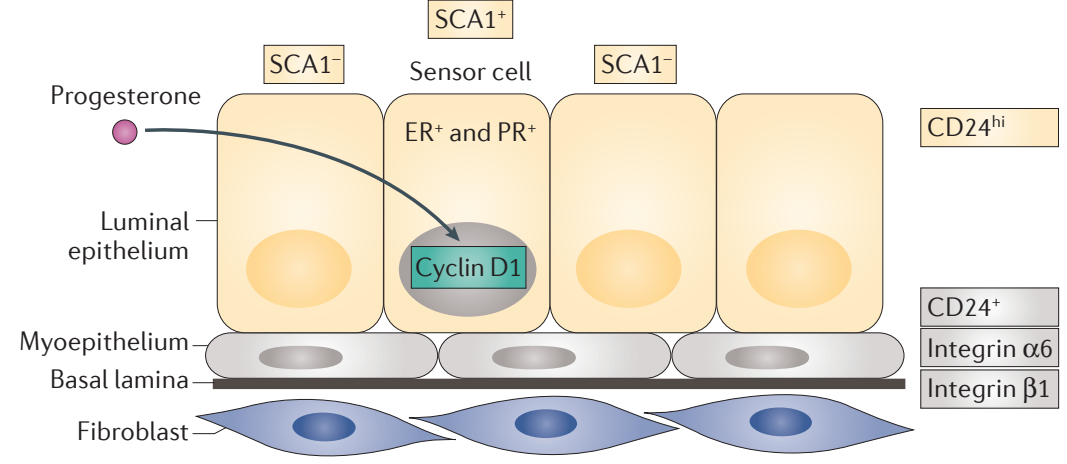

\section{b Cell proliferation: paracrine}

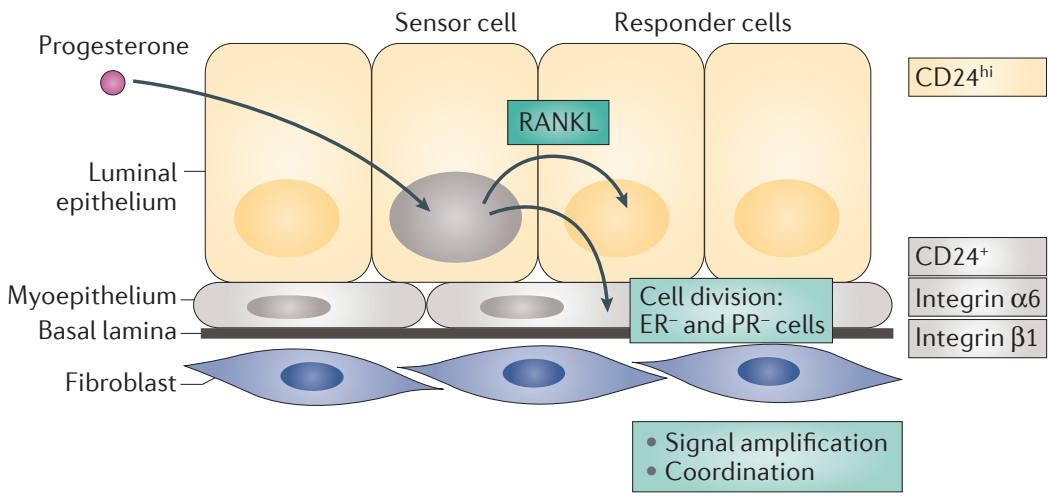

Figure 5 | Models of cell-intrinsic and paracrine mechanisms of progesteroneinduced cell proliferation in the mouse mammary epithelium. A hormone receptor $(\mathrm{HR})^{+}$cell is indicated by a grey nucleus. Progesterone elicits proliferation of $\mathrm{HR}^{+}$cells by a cell-intrinsic, cyclin D1-dependent mechanism (part a). The hormone also induces the expression of receptor activator of nuclear factor- $\mathrm{B}$ (NF- $\mathrm{k}$ ) ligand (RANKL) secretion, which triggers the proliferation of adjacent $\mathrm{HR}^{-}$cells (part b). Luminal and basal cells can be separated by fluorescence-activated cell sorting on the basis of high cell surface expression of CD24 or integrin $\beta 1$ and integrin $\alpha 6$, respectively. The luminal (CD24hi) cell population can be divided into $\mathrm{HR}^{+}$and $\mathrm{HR}^{-}$cells on the basis of the presence or absence of stem cell antigen 1 (SCA1). ER, oestrogen receptor; PR, progesterone receptor.

double-transgenic approach, resulted in side branching and alveologenesis ${ }^{74}$. Similarly, ectopic RANKL expression in $\mathrm{Pgr}^{-1-}$ mammary epithelium by means of a retroviral approach, rescued the $\mathrm{Pgr}^{-1-}$ phenotype, indicating that RANKL is a crucial mediator of PR signalling function. Immunohistochemistry shows RANKL is present at the cell membrane, but whether it impinges on the neighbouring cells in this membrane-bound form or is secreted is unclear. Of clinical relevance, soluble RANKL administered intravenously can elicit proliferation in the mammary epithelium, and systemic administration of its decoy receptor osteoprotegerin (OPG) can inhibit proliferation ${ }^{35}$.

Mammary stem cells. FACS experiments combined with cleared fat pad reconstitution assays revealed that high expression of integrin $\alpha 6$ and integrin $\beta 1$ enriches for cells with basal characteristics that are able to reconstitute ductal trees in mammary fat pads devoid of endogenous epithelium. This led to the definition of these cells as mammary stem cells. Cells lacking these markers have luminal characteristics and fail to reconstitute ductal trees in cleared fat pads. Instead, they give rise to cystic structures ${ }^{58}$. Both oestrogens and progesterone were implicated in mammary stem cell activation on the basis of an increase in the number of integrin $a 6^{+}$cells after hormone stimulation of ovariectomized mice ${ }^{75,76}$. RANKL was implicated in this hormone-induced stem cell expansion on the basis of the decreased in vitro clonogenic capacity of integrin $\beta 1^{+} \mathrm{CD} 24^{+}$cells harvested from mammary glands after in vivo treatment with an antibody against RANKL ${ }^{76}$. Furthermore, genetic ablation of the RANKL receptor RANK abrogated a twofold increase in the integrin $a 6^{+}$compartment induced by progestin treatment ${ }^{77}$, suggesting that RANKL may activate the stem cells as a paracrine factor.

Conversely, recent lineage-tracing experiments have provided evidence that the totipotent stem cell function may be provoked by the particular experimental conditions and may not be relevant to normal physiological homeostasis. Indeed, luminally and myoepithelially restricted progenitors are sufficient to maintain the postnatal gland ${ }^{78,79}$. This raises the question of whether RANKL or the other paracrine factors such as WNT4 and amphiregulin may function selectively on one or the other types of lineage-restricted progenitors.

Other biological functions and factors. Along with cell proliferation and the expansion of the progenitor cells, other biological processes are required to prepare the gland for copious milk production after the birth of pups in the mouse model. A large amount of ECM needs to be restructured in the process, and angiogenesis is required to feed new ducts and to subsequently bring in the nutrients that are necessary for milk production. Different types of immune cells help to build most of the transient structures required for lactation, and subsequently help to destroy them and clear away the cellular debris. Various matrix metalloproteinases (MMPs) and the associated tissue inhibitors of metalloproteinases (TIMPs) have been implicated ${ }^{80}$ but how they are linked to hormonal pathways remains to be elucidated. A complex interplay between multiple cell types is to be expected. Powerful in vivo imaging approaches have shown us some of the activities of macrophages in the mammary gland ${ }^{81}$ and promise to provide novel insights in the future.

Genetic evidence has been provided that WNT4 is an important mediator of PR signalling. In the absence of WNT4 from the mammary epithelium, side branching is delayed. Ectopic expression of its cousin WNT1 can rescue side branching by a paracrine mechanism in the absence of PR signalling ${ }^{56}$. Similarly, inhibitor of DNA binding 4 (ID4), a basic helix-loop-helix (bHLH) protein that is predominantly expressed in the myoepithelium is induced by progesterone, and its deletion in the mammary epithelium blocks side branching ${ }^{82}$. Calcitonin and amphiregulin have also been identified as in vivo progesterone targets ${ }^{83}$. Deletion of amphiregulin revealed a role for oestrogen-induced proliferation during pubertal ductal elongation ${ }^{53}$. This early phenotype 


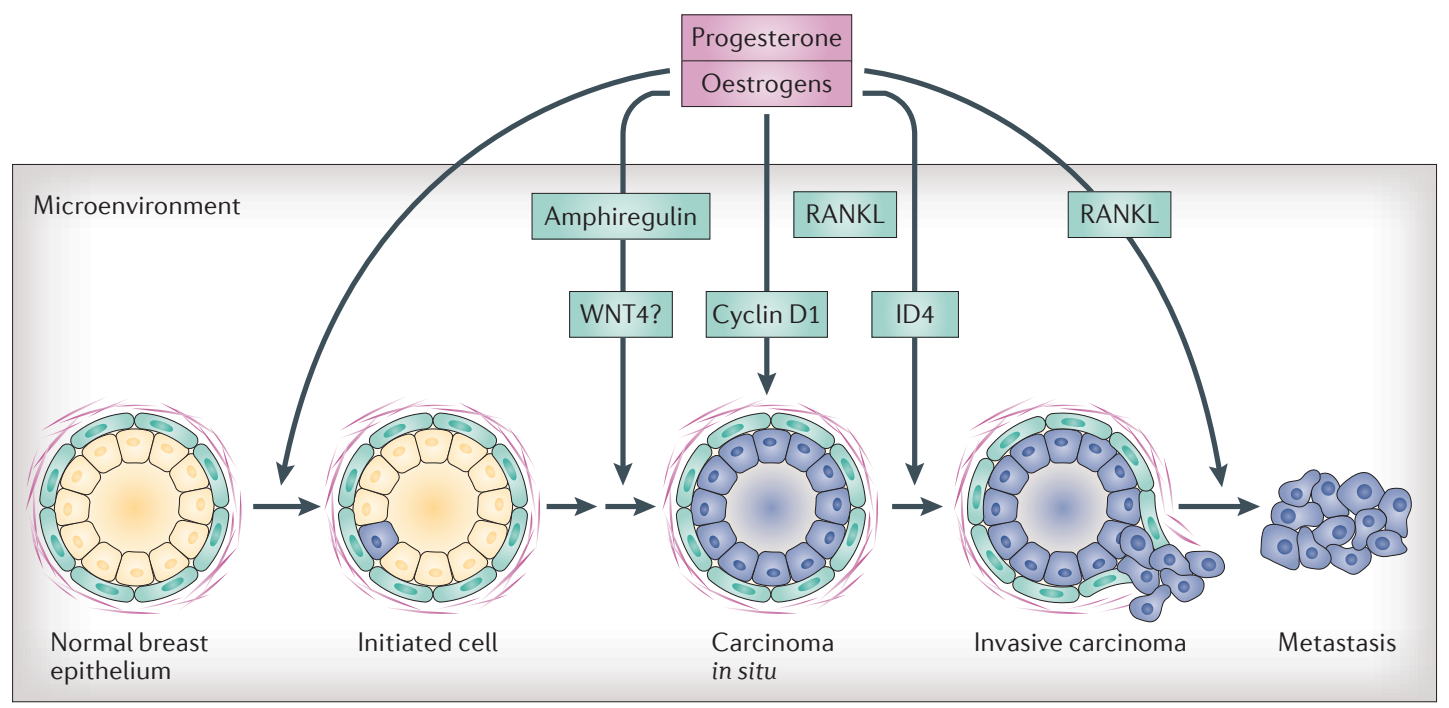

Figure 6 | Model of breast carcinogenesis. Shown are schematic cross sections of a milk duct with luminal (beige) and outer myoepithelial cells (green) that are surrounded by a basement membrane (pink). Analogously to the Vogelstein model of colon cancer progression ${ }^{97}$, successive stages of breast tumorigenesis are shown. Early stages of breast carcinogenesis are poorly characterized. Hormones impinge on all stages of breast cancer development. In particular, progesterone signalling is important in determining whether pre-existing lesions progress to clinically relevant tumours; that is, invasive and metastatic breast cancer. Progesterone changes the microenvironment, and it activates a number of pathways that have been implicated in the genesis of different subtypes of breast cancer in the mouse mammary gland that control intercellular communication. I hypothesize that repeated activation of these pathways during the luteal phase of menstrual cycles promotes breast carcinogenesis. Some of these such as amphiregulin ${ }^{98}$, receptor activator of nuclear factor- $\kappa \mathrm{B}$ (NF- $\kappa \mathrm{B}$ ) ligand (RANKL) ${ }^{99}$ and inhibitor of DNA binding 4 (ID4) ${ }^{100}$ have indeed been implicated in the genesis of distinct human breast cancer subtypes.

imposes a developmental block that may mask any additional role during side branching. Therefore, defining the exact contributions of these different aspects of progesterone-induced differential gene expression will require further studies. The elucidation of these processes will provide us with important insights into the clinically relevant question of how in situ lesions progress to invasive disease.

\section{Progesterone signalling and breast cancer}

What are the implications of these findings for breast cancer? It is conceivable that during repeated menstrual cycles, recurrent activation of PR and its downstream effectors, cyclin D1, WNT4 and RANKL promotes breast carcinogenesis (FIG. 6). Indeed, administration of the PR agonist medroxy-progesterone acetate (MPA) to mice promotes the formation of mammary tumours initiated by $\mathrm{DMBA}^{84}$. Such MPA- and DMBA-induced tumorigenesis is slowed both by pharmacologically and by genetically interfering with RANKL signalling ${ }^{77,85}$. Constitutive activation of the well-established signalling pathways downstream of PR is also oncogenic. Ectopic RANK expression in the mammary epithelium driven by the mouse mammary tumour virus (MMTV) promoter increases proliferation in the mammary epithelium ${ }^{86}$ and accelerates DMBA- and progestin-induced tumorigenesis ${ }^{85}$.

Another downstream pathway, the WNT signalling pathway, has long been identified as oncogenic in the mouse mammary gland. In fact, the first WNT gene to be cloned was identified as a frequent integration site for $\mathrm{MMTV}^{87}$. Its ectopic expression results in extensive ductal hyperplasia and tumours ${ }^{88}$.

Using freshly isolated human breast tissue microstructures we have found that expression of both RANKL and WNT4 mRNA is induced by PR signalling ${ }^{47}$. Moreover, RANKL is sufficient to elicit cell proliferation and is required for progesterone-induced proliferation. The findings in the ex vivo system were validated by the in vivo observation that RANKL protein expression correlated with serum progesterone levels in women ${ }^{47}$.

These findings offer exciting perspectives as they suggest that at least some of the pathways are conserved between mice and humans and that they may contribute to tumorigenesis. Hence novel preventive strategies can be envisioned that are based on inhibiting PR and its downstream mediators RANKL and WNT. Newgeneration selective progesterone receptor modulators (SPRMs) that have fewer side effects than earlier ones, have been developed for various gynaecological disorders such as myomas, bleeding endometriosis and other reproductive problems, and may turn out to be useful for patients with breast cancer. Furthermore, an antibody against RANKL, denosumab, is already US Food and Drug Administration (FDA)-approved for the treatment of postmenopausal women who are at a high risk of fractures and for the prevention of skeletal complications in patients with bone metastases. WNT inhibitors are being developed and are undergoing clinical testing ${ }^{89}$. 
Selective oestrogen receptor modulators (SERMs). Compounds (such as tamoxifen and raloxifene) that act on the oestrogen receptor (ER). They can have different effects in different tissues, allowing selective inhibition or stimulation of ER.
Interfering pharmacologically with menstrual cycle-induced activation of the breast (as described above), may be of particular use in young patients with breast cancer. Women under 40 years of age who have breast cancer have a $5 \%$ risk of developing a second tumour in the contralateral breast within 10 years. Interfering with the breast-specific effects of increased serum progesterone levels may be an effective way to reduce their risk of dying of breast cancer without blocking all reproductive function. SPRMs could also be envisioned as adjuvant treatment in scenarios in which selective oestrogen receptor modulators (SERMs) or aromatase inhibitors are not well tolerated.

With regards to the ability of such drugs to act on established tumours and in advanced disease, important questions need to be addressed. Are the paracrine mechanisms discussed above active in human tumours? It is important to remember that $\mathrm{ER}^{+}$tumours are defined by immunhistochemistry as having at least $1 \%$ of tumour cells that stain for ERa. Hence, they comprise a whole range of tumours with anything from $1 \%$ to $100 \%$ of the tumour cells expressing ERa. It is conceivable that paracrine signalling is more important for tumours with a low proportion of $\mathrm{ER}^{+}$cells than for the majority of $E R \alpha^{+}$tumours, which show widespread $\mathrm{ER} \alpha$ expression. In $\mathrm{ER}^{+}$tumours ERa expression and thymidine incorporation coexist in a large proportion of the cells. Is this proliferation induced by cell-intrinsic and/or by paracrine mechanisms?

Are the paracrine loops active in the metastatic niche? Are they activated by ERa or PR expressed by the tumour cells or perhaps by hormone-responsive bone cells? In the MMTV-Erbb2 tumour model, infiltrating $\mathrm{T}$ cells have been shown to stimulate metastasis by releasing RANKL $\mathrm{L}^{90}$, suggesting that paracrine loops also involve an immune cell component, at least in tumorigenesis.

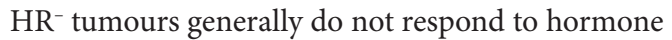
therapy and are thought to bypass the requirement for hormones by constitutively activating cell-intrinsic growth-promoting pathways. The specific growthpromoting pathways chosen may represent a characteristic of a particular tumour or a subset of cells within a given tumour. In their early stages, and possibly in the process of metastatic seeding, there may be hormonesensitive steps in their progression, as suggested by the finding that menstrual cycles increase the risk for all types of breast cancers.

Blocking the hormone-induced activation of a protumorigenic microenvironment, either in the breast or at distant sites in the body, by interfering with hormone signalling and downstream pathways, may help to prevent disease progression. It could then form the basis of an adjuvant therapy in women diagnosed with early stage disease, many of whom are currently overtreated with chemotherapy.

\section{Perspectives}

Thanks to high-throughput sequencing approaches, our knowledge of the molecular genetics of breast cancer is increasing much faster than our understanding of mammary gland biology and pathology. Reproductive hormones impinge on breast carcinogenesis at all stages and can determine whether the disease will progress (FIG. 6). In particular, PR signalling has a pivotal role in controlling tumour promotion from the in situ stage onwards. The insight that systemic hormones use locally produced paracrine factors to mediate their effects offers new opportunities for intervention. Such novel approaches may allow us to 'deactivate' a tumourpromoting microenvironment, an approach that may also help to prevent tumour progression and metastasis. How genetic mutations in tumour cells synergize with changes in the microenvironment elicited by hormones will be a challenging area to explore.
1. Lakhani, S. R., Ellis, I. O., Schnitt, S. J., Tan, P. H. \& van de Vijver, M. J. in WHO Classification of Tumors of the Breast. (eds Tavassoli, F. \& Devilee, P.) 13-59 (IARC Press, 2012).

2. Cancer Genome Atlas Network. Comprehensive molecular portraits of human breast tumours. Nature 490, 61-70 (2012).

3. Banerii, S. et al. Sequence analysis of mutations and translocations across breast cancer subtypes. Nature 486, 405-409 (2012).

4. Marusyk, A., Almendro, V. \& Polyak, K. Intra-tumour heterogeneity: a looking glass for cancer? Nature Rev. Cancer 12, 323-334 (2012).

5. Almendro, V., Marusyk, A. \& Polyak, K. Cellular heterogeneity and molecular evolution in cancer. Annu. Rev. Pathol. 8, 277-302 (2012).

6. Nielsen, M., Thomsen, J. L., Primdahl, S., Dyreborg, U. \& Andersen, J. A. Breast cancer and atypia among young and middle-aged women: a study of 110 medicolegal autopsies. Br. J. Cancer 56, 814-819 (1987).

This study shows that about $30 \%$ of women in their forties have DCIS or DCIS-like lesions in their breasts.

7. Buerger, H. et al. Comparative genomic hybridization of ductal carcinoma in situ of the breast-evidence of multiple genetic pathways. J. Pathol. 187, 396-402 (1999).

8. Nandi, S. Endocrine control of mammary-gland development in the $\mathrm{C} 3 \mathrm{H} / \mathrm{He} \mathrm{Crgl}$ mouse. J. Natl Cancer Inst. 21, 1039-1063 (1958).
9. Lyons, W. R. Hormonal synergism in mammary growth. Proc. R. Soc. Lond. B Biol. Sci. 149, 303-325 (1958)

10. MacMahon, B. et al. Age at first birth and breast cancer risk. Bull. World Health Organ. 43, 209-221 (1970).

11. Colditz, G. A., Rosner, B. A., Chen, W. Y., Holmes, M. D. \& Hankinson, S. E. Risk factors for breast cancer according to estrogen and progesterone receptor status. J. Natl Cancer Inst. 96, 218-228 (2004)

12. Pike, M. C. Krailo, M. D., Henderson, B. E., Casagrande, J.T. \& Hoel, D. G. 'Hormonal' risk factors, 'breast tissue age' and the age-incidence of breast cancer. Nature 303, 767-770 (1983). This early study highlights that, unlike other cancers, breast cancer does not simply increase exponentially with age and proposes a model for 'breast tissue age'.

13. Masters, J. R., Drife, J. O. \& Scarisbrick, J. J. Cyclic Variation of DNA synthesis in human breast epithelium. J. NatI Cancer Inst. 58, 1263-1265 (1977).

14. Longacre, T. A. \& Bartow, S. A. A correlative morphologic study of human breast and endometrium in the menstrual cycle. Am. J. Surg. Pathol. 10, 382-393 (1986).

15. Wellings, S. R. \& Jensen, H. M. On the origin and progression of ductal carcinoma in the human breast. J. Natl Cancer Inst. 50, 1111-1118 (1973).
16. Beatson, G. T. On the treatment of inoperable cases of carcinoma of the mamma: suggestions for a new method of treatment, with illustrative cases. Lancet, 104-107 (1896).

17. Early Breast Cancer Trialists' Collaborative Group (EBCTCG). Effects of chemotherapy and hormonal therapy for early breast cancer on recurrence and 15-year survival: an overview of the randomised trials. Lancet $365,1687-1717$ (2005).

18. Collaborative Group on Hormonal Factors in Breast Cancer. Breast cancer and hormonal contraceptives: collaborative reanalysis of individual data on 53 297 women with breast cancer and 100239 women without breast cancer from 54 epidemiological studies. Lancet 347, 1713-1727 (1996).

19. Anderson, G. L. et al. Conjugated equine oestrogen and breast cancer incidence and mortality in postmenopausal women with hysterectomy: extended follow-up of the Women's Health Initiative randomised placebo-controlled trial. Lancet Oncol. 13, 476-486 (2012).

20. Beral, V. Breast cancer and hormone-replacement therapy in the Million Women Study. Lancet 362, 419-427 (2003).

21. Chlebowski, R. T. et al. Estrogen plus progestin and breast cancer incidence and mortality in postmenopausal women. JAMA 304, 1684-1692 (2010). 
22. Rossouw, J. E. et al. Risks and benefits of estrogen plus progestin in healthy postmenopausal women: principal results from the Women's Health Initiative randomized controlled trial. JAMA 288, 321-333 (2002).

23. Hofseth, L. J. et al. Hormone replacement therapy with estrogen or estrogen plus medroxyprogesterone acetate is associated with increased epithelial proliferation in the normal postmenopausal breast. J. Clin. Endocrinol. Metab. 84, 4559-4565 (1999).

24. Fournier, A., Berrino, F. \& Clavel-Chapelon, F. Unequal risks for breast cancer associated with different hormone replacement therapies: results from the E3N cohort study. Breast Cancer Res. Treat. 107, 103-111 (2008).

25. Fournier, A., Berrino, F., Riboli, E., Avenel, V. \& ClavelChapelon, F. Breast cancer risk in relation to different types of hormone replacement therapy in the E3N-EPIC cohort. Int. J. Cancer 114, 448-454 (2005).

26. Sitruk-Ware, R. Pharmacological profile of progestins. Maturitas 47, 277-283 (2004).

27. Farhat, G. N., Walker, R., Buist, D. S., Onega, T. \& Kerlikowske, K. Changes in invasive breast cancer and ductal carcinoma in situ rates in relation to the decline in hormone therapy use. J. Clin. Oncol. 28, 5140-5146 (2010).

28. Chlebowski, R. T. et al. Breast cancer after use of estrogen plus progestin in postmenopausal women. N. Engl. J. Med. 360, 573-587 (2009).

29. McCormack, V. A. \& dos Santos Silva, I. Breast density and parenchymal patterns as markers of breast cancer risk: a meta-analysis. Cancer Epidemiol. Biomarkers Prev. 15, 1159-1169 (2006).

30. Boyd, N. F. et al. Mammographic density and the risk and detection of breast cancer. N. Engl. J. Med. 356, 227-236 (2007)

31. Lundstrom, E. et al. Effects of tibolone and continuous combined hormone replacement therapy on mammographic breast density. Am. J. Obstet. Gynecol. 186, 717-722 (2002).

32. Vachon, C. M., Sellers, T. A., Vierkant, R. A., Wu, F. F. \& Brandt, K. R. Case-control study of increased mammographic breast density response to hormone replacement therapy. Cancer Epidemiol. Biomarkers Prev. 11, 1382-1388 (2002).

33. Greendale, G. A. et al. Postmenopausal hormone therapy and change in mammographic density. J. Natl Cancer Inst. 95, 30-37 (2003).

34. Daniel, C. W., Silberstein, G. B. \& Strickland, P. Direct action of $17 \beta$-estradiol on mouse mammary ducts analyzed by sustained release implants and steroid autoradiography. Cancer Res. 47, 6052-6057 (1987).

35. Beleut, M. et al. Two distinct mechanisms underlie progesterone-induced proliferation in the mammary gland. Proc. Natl Acad. Sci. USA 107, 2989-2994 (2010).

36. Wang, S., Counterman, L. J. \& Haslam, S. Z. Progesterone action in normal mouse mammary gland. Endocrinology 127, 2183-2189 (1990).

37. Haslam, S. Z. \& Shyamala, G. Effect of oestradiol on progesterone receptors in normal mammary glands and its relationship with lactation. Biochem. J. 182 127-131 (1979)

38. Aupperlee, M. D. \& Haslam, S. Z. Differential hormonal regulation and function of progesterone receptor isoforms in normal adult mouse mammary gland. Endocrinology 148, 2290-2300 (2007).

39. Lydon, J. et al. Mice lacking progesterone receptor exhibit pleiotropic reproductive abnormalities. Genes Dev 9, 2266-2278 (1995).

40. Dupont, S. et al. Effect of single and compound knockouts of estrogen receptors $\alpha(E R \alpha)$ and $\beta(E R \beta)$ on mouse reproductive phenotypes. Development 127, 4277-4291 (2000).

41. Mallepell, S., Krust, A., Chambon, P. \& Brisken, C. Paracrine signaling through the epithelial estrogen receptor $\alpha$ is required for proliferation and morphogenesis in the mammary gland. Proc. Natl Acad. Sci. USA 103, 2196-2201 (2006)

42. Brisken, C. et al. A paracrine role for the epithelial progesterone receptor in mammary gland development. Proc. Natl Acad. Sci. USA 95, 5076-5081 (1998). This study provided genetic evidence that epithelial intrinsic progesterone signalling is important for mammary gland side branching and that progesterone can function by paracrine mechanisms.

43. Brisken, C. \& O'Malley, B. Hormone action in the mammary gland. Cold Spring Harb. Perspect. Biol. 2 a003178 (2011).
44. Walmer, D. K., Wrona, M. A., Hughes, C. L. \& Nelson, K. G. Lactoferrin expression in the mouse reproductive tract during the natural estrous cycle: correlation with circulating estradiol and progesterone. Endocrinology 131, 1458-1466 (1992).

45. Caligioni, C. S. Assessing reproductive status/stages in mice. Curr. Protoc. Neurosci. 4, Appendix 41 (2009).

46. Chow, J. D., Simpson, E. R. \& Boon, W. C. Alternative 5'-untranslated first exons of the mouse Cyp 19A1 (aromatase) gene. J. Steroid Biochem. Mol. Biol. 115, 115-125 (2009).

47. Tanos, T. et al. Progesterone/RANKL is a major regulatory axis in the human breast. Sci. Transl. Med. 5, 182 ra55 (2013).

48. Clarke, R. B., Howell, A., Potten, C. S. \& Anderson, E. Dissociation between steroid receptor expression and cell proliferation in the human breast. Cancer Res. 57, 4987-4991 (1997)

This study showed that in the normal human breast epithelium, cell proliferation and hormone receptor expression are dissociated, whereas in breast cancer samples ERa ${ }^{+}$cells frequently proliferate.

49. Grimm, S. L. et al. Disruption of steroid and prolactin receptor patterning in the mammary gland correlates with a block in lobuloalveolar development. $\mathrm{Mol}$. Endocrinol. 16, 2675-2691 (2002).

50. Seagroves, T. N., Lydon, J. P., Hovey, R. C., Vonderhaar, B. K. ¿ Rosen, J. M. C/EBPß (CCAAT/ enhancer binding protein) controls cell fate determination during mammary gland development. Mol. Endocrinol. 14, 359-368 (2000).

51. Russo, J., Ao, X., Grill, C. \& Russo, I. H. Pattern of distribution of cells positive for estrogen receptor $\alpha$ and progesterone receptor in relation to proliferating cells in the mammary gland [In Process Citation] Breast Cancer Res. Treat. 53, 217-227 (1999)

52. Ewan, K. B. et al. Proliferation of estrogen receptor- $\alpha-$ positive mammary epithelial cells is restrained by transforming growth factor- $\beta 1$ in adult mice. $A m$. J. Pathol. 167, 409-417 (2005).

53. Ciarloni, L., Mallepell, S. \& Brisken, C. Amphiregulin is an essential mediator of estrogen receptor $\alpha$ function in mammary gland development. Proc. Natl Acad. Sci. USA 104, 5455-5460 (2007).

54. Kariagina, A., Xie, J., Leipprandt, J. R. \& Haslam, S. Z . Amphiregulin mediates estrogen, progesterone, and EGFR signaling in the normal rat mammary gland and in hormone-dependent rat mammary cancers. Horm. Cancer 1, 229-244 (2010).

55. Fata, J. E. et al. The osteoclast differentiation factor osteoprotegerin-ligand is essential for mammary gland development. Cell 103, 41-50 (2000) This was the first study to identify a role for RANKL in mammary gland development.

56. Brisken, C et al. Essential function of Wnt-4 in mammary gland development downstream of progesterone signaling. Genes Dev 14, 650-654 (2000)

57. Reid, G. et al. Cyclic, proteasome-mediated turnover of unliganded and liganded $\mathrm{ER} \alpha$ on responsive promoters is an integral feature of estrogen signaling. Mol. Cell 11, 695-707 (2003).

58. Sleeman, K. E., Kendrick, H., Ashworth, A., Isacke, C. M. \& Smalley, M. J. CD24 staining of mouse mammary gland cells defines luminal epithelial, myoepithelial/basal and non-epithelial cells. Breast Cancer Res. 8, R7 (2006)

59. Sleeman, K. E. et al. Dissociation of estrogen receptor expression and in vivo stem cell activity in the mammary gland. J. Cell Biol. 176, 19-26 (2007).

60. Kendrick, H. et al. Transcriptome analysis of mammary epithelial subpopulations identifies novel determinants of lineage commitment and cell fate. BMC Genomics 9, 591 (2008).

61. Oakes, S. R. et al. The Ets transcription factor Elf5 specifies mammary alveolar cell fate. Genes Dev. 22 581-586 (2008)

62. Perou, C. M. et al. Molecular portraits of human breast tumours. Nature 406, 747-752 (2000)

63. Hennessy, B. T. et al. Characterization of a naturally occurring breast cancer subset enriched in epithelial-to-mesenchymal transition and stem cell characteristics. Cancer Res. 69, 4116-4124 (2009)

64. Farmer, P. et al. Identification of molecular apocrine breast tumours by microarray analysis. Oncogene $\mathbf{2 4}$, 4660-4671 (2005)

65. Roy, P. G. et al. High CCND1 amplification identifies a group of poor prognosis women with estrogen receptor positive breast cancer. Int. J. Cancer 127 355-360 (2010).
66. Kenny, F. S. et al. Overexpression of cyclin D1 messenger RNA predicts for poor prognosis in estrogen receptor-positive breast cancer. Clin. Cancer Res. 5, 2069-2076 (1999).

67. Rudas, M. et al. Cyclin D1 expression in breast cance patients receiving adjuvant tamoxifen-based therapy. Clin. Cancer Res. 14, 1767-1774 (2008).

68. Stendahl, M. et al. Cyclin D1 overexpression is a negative predictive factor for tamoxifen response in postmenopausal breast cancer patients. Br. J. Cancer 90, 1942-1948 (2004)

69. Fu, M., Wang, C., Li, Z., Sakamaki, T. \& Pestell, R. G. Minireview: Cyclin D1: normal and abnormal functions. Endocrinology 145, 5439-5447 (2004).

70. Kong, Y. Y. et al. OPGL is a key regulator of osteoclastogenesis, lymphocyte development and lymph-node organogenesis. Nature 397, 315-323 (1999).

71. Cao, Y. et al. IKK $\alpha$ provides an essential link between RANK signaling and cyclin D1 expression during mammary gland development. Cell 107, 763-775 (2001).

72. Brisken, C. et al. IGF-2 is a mediator of prolactininduced morphogenesis in the breast. Dev. Cell 3 877-887 (2002)

73. Mulac-Jericevic, B., Lydon, J. P., DeMayo, F. J. \& Conneely, O. M. Defective mammary gland morphogenesis in mice lacking the progesterone receptor B isoform. Proc. Natl Acad. Sci. USA 100, 9744-9749 (2003).

74. Mukherjee, A. et al. Targeting RANKL to a specific subset of murine mammary epithelial cells induces ordered branching morphogenesis and alveologenesis in the absence of progesterone receptor expression. FASEB J. 24, 4408-4419 (2010).

75. Joshi, P. A. et al. Progesterone induces adult mammary stem cell expansion. Nature 465, 803807 (2010).

76. Asselin-Labat, M. L. et al. Control of mammary stem cell function by steroid hormone signalling. Nature 465, 798-802 (2010)

77. Schramek, D. et al. Osteoclast differentiation factor RANKL controls development of progestin-driven mammary cancer. Nature 468, 98-102 (2010). This study provided genetic evidence for a role of RANK signalling in mouse mammary tumorigenesis.

78. Van Keymeulen, A. et al. Distinct stem cells contribute to mammary gland development and maintenance. Nature 479, 189-193 (2011).

79. van Amerongen, R. Bowman, A. N \& Nusse, R. Developmental stage and time dictate the fate of Wnt/ $\beta$-catenin-responsive stem cells in the mammary gland. Cell Stem Cell 11, 387-400 (2012)

80. Lu, P., Takai, K., Weaver, V. M. \& Werb, Z. Extracellular matrix degradation and remodeling in development and disease. Cold Spring Harb. Perspect. Biol. 3, a005058 (2011).

81. Ingman, W. V., Wyckoff, J., Gouon-Evans, V., Condeelis, J. \& Pollard, J. W. Macrophages promote collagen fibrillogenesis around terminal end buds of the developing mammary gland. Dev. Dyn. 235, 3222-3229 (2006).

82. Dong, J. et al. ID4 regulates mammary gland development by suppressing p38MAPK activity. Development 138, 5247-5256 (2011).

83. Fernandez-Valdivia, R. et al. Transcriptional response of the murine mammary gland to acute progesterone exposure. Endocrinology 149, 6236-6250 (2008).

84. Aldaz, C. M., Liao, Q. Y., LaBate, M. \& Johnston, D. A Medroxyprogesterone acetate accelerates the development and increases the incidence of mouse mammary tumors induced by dimethylbenzanthracene. Carcinogenesis 17, 20692072 (1996).

85. Gonzalez-Suarez, E. et al. RANK ligand mediates progestin-induced mammary epithelial proliferation and carcinogenesis. Nature 468, 103-107 (2010). This study showed that pharmacological inhibition of RANK signalling in a mouse mammary tumour model slows tumour development.

86. Gonzalez-Suarez, E. et al. RANK overexpression in transgenic mice with mouse mammary tumor virus promoter-controlled RANK increases proliferation and impairs alveolar differentiation in the mammary epithelia and disrupts lumen formation in cultured epithelial acini. Mol. Cell. Biol. 27, 1442-1454 (2007).

87. Nusse, R. \& Varmus, H. Many tumors induced by the mouse mammary tumor virus contain a provirus integrated in the same region of the host genome. Cell 31, 99-109 (1982). 
88. Tsukamoto, A., Grosschedl, R., Guzman, R., Parslow, T $\S$ Varmus, $\mathrm{H}$. Expression of the int-1 gene in transgenic mice is associated with mammary gland hyperplasia and adenocarcinomas in male and female mice. Cell 55, 619-625 (1988).

89. Anastas, J. N. \& Moon, R. T. WNT signalling pathways as therapeutic targets in cancer. Nature Rev. Cancer 13, 11-26 (2012).

90. Tan, W. et al. Tumour-infiltrating regulatory T cells stimulate mammary cancer metastasis through RANKL-RANK signalling. Nature 470, 548-553 (2011).

91. Huggins, C., Briziarelli, G. \& Sutton, H. Jr. Rapid induction of mammary carcinoma in the rat and the influence of hormones on the tumors. J. Exp. Med. 109, 25-42 (1959).

92. Cheung, S. Y. et al. An expression study of hormone receptors in spontaneously developed, carcinogeninduced and hormone-induced mammary tumors in female Noble rats. Int. J. Oncol. 22, 1383-1395 (2003).

93. Graham, J. D. et al. Altered progesterone receptor isoform expression remodels progestin responsiveness of breast cancer cells. Mol. Endocrinol. 19, 2713-2735 (2005)

94. Mulac-Jericevic, B., Mullinax, R. A., DeMayo, F. J., Lydon, J. P. \& Conneely, O. M. Subgroup of reproductive functions of progesterone mediated by progesterone receptor-B isoform. Science 289 1751-1754 (2000)

95. Richer, J. K. et al. Differential gene regulation by the two progesterone receptor isoforms in human breast cancer cells. J. Biol. Chem. 277, 5209-5218 (2002)

96. Aupperlee, M. D., Smith, K. T., Kariagina, A. $\delta$ Haslam, S. Z. Progesterone receptor isoforms A and $B$ : temporal and spatial differences in expression during murine mammary gland development. Endocrinology 146, 3577-3588 (2005).

97. Fearon, E. R. \& Vogelstein, B. A genetic model for colorectal tumorigenesis. Cell 61, 759-767 (1990).

98. Lee, S. et al. Alterations of gene expression in the development of early hyperplastic precursors of breast cancer. Am. J. Pathol. 171, 252-262 (2007).

99. Palafox, M. et al. RANK induces epithelialmesenchymal transition and stemness in human mammary epithelial cells and promotes tumorigenesis and metastasis. Cancer Res. 72, 2879-2888 (2012).

100. Wen, Y. H. et al. Id4 protein is highly expressed in triple-negative breast carcinomas: possible implications for BRCA1 downregulation. Breast Cancer Res. Treat. 135, 93-102 (2012).

\section{Acknowledgements}

The author apologizes for the numerous studies she could not mention because of space constraints, and thanks $C$. Lebrand, R. Iggo, and M. Fiche for critical reading of the manuscript and valuable suggestions.

Competing interests statement

The author declares no competing financial interests.

\section{FURTHER INFORMATION}

Cathrin Brisken's homepage: http://brisken-lab.epfl.ch

Molecular and Cellular Endocrinology issue on Molecular mechanisms of action in progesterone signalling: http://

www.sciencedirect.com/science/journal/03037207/357/1-2

ALL LINKS ARE ACTIVE IN THE ONLINE PDF 